\title{
ATUAÇÃO DA ENFERMEIRA DE SAÚDE PÚBLICA NO PROGRAMA DE SAÚDE MENTAL DE UM CENTRO DE SAÚDE
}

\author{
Ester B. Barros * \\ Reinaldo S. Correia ** \\ Nereide A. Herrera $* * *$ \\ José Carlos Seixas ***
}

I - Introdução

Desde a instalação do Centro de Saúde Experimental da Barra Funda em 1969, com os dados resultantes da apuração do censo demográfico, a equipe de Saúde foi alertada quanto a possíveis problemas na área de Saúde Mental. A partir de março de 1972, iniciou-se uma programação de Saúde Mental com finalidades específicas.

\section{II - Justificativas}

Considerando que:

1 - A equipe do Centro de Saúde, responsável pela programação de Saúde Pública nos subdistritos da Barra Funda e do Bom

* Instrutora do Departamento de Medicina Social da Faculdade de Ciências Médicas da Santa Casa de Misericórdia de São Paulo e enfermeira de Saúde Pública do Centro de Saúde Experimental da Barra Funda e Bom Retiro, São Paulo.

** Professor Assistente do Departamento de Psiquiatria da Faculdade de Ciências Médicas da Santa Casa de Misericórdia de São Paulo.

*** Instrutora do Departamento de Medicina Social da Faculdade de Ciências Médicas da Santa Casa de São Paulo e Assistente Social do Centro de Saúde Experimental da Barra Funda e Bom Retiro.

**** Professor Associado do Departamento de Medicina Social da Faculdade de Ciências Médicas da Santa Casa de Misericórdia de Sãc Paulo. Instrutor do Departamento de Prática de Saúde Pública; Médico-Sanitarista do Centro de Saúde Experimental da Barra Funda e do Bom Retiro. 
Retiro não desconhecia as referências técnico-científicas que a alertaram quanto a prioridade das atividades médico-sanitaria-psiquiatricas;

2 - Por dificuldades financeiras para contar com pessoal especializado na área de Saúde Mental, bem como por falta de técnicas consagradas e de eficiência comprovadas na mesma área, em Saúde Pública, vinha o Centro de Saúde atuando até início de 1972, com relação aos problemas de natureza psíquica, encaminhando os casos para instituições especializadas e de orientação psicológica por profissionais não especificamente da área;

3 - Após 2 anos de atuação junto à população, foi-se confirmando na prática a importância e exigência de uma programação específica em Saúde Mental;

4 - Podendo a partir de 1972 contar com a participação de um médico-psiquiatra, pode o Centro de Saúde sistematizar e programar uma atuação específica na área de Saúde Mental.

III - Diretrizes básicas do programa de Saúde Mental

Alguns pontos de vista foram firmados pela equipe do Centro de Saúde com relação à programação de Saúde Mental:

1 - Ao nível de um Centro de Saúde, dever-se-ia atuar psiquiatricamente da mesma forma que se atua com relação às demais doenças, isto é, considerando objetos de diagnósticos e tratamento aquelas doenças que tenham uma alta prevalência e que determinam repercussões sociais indesejáveis;

2 - Nesta programação, deveriam ser utilizadas técnicas disponíveis e aplicáveis ao maior número possível de pessoas.

3 - A repercussão social significativa seria determinada à medida em que os possíveis doentes pudessem ser reconhecidos por qualquer membro da equipe de saúde, através da manifestação dos distúrbios psíquicos em seus meios familiar e social.

4 - A atuação da equipe seria baseada nos níveis de prevenção propostos por Leavell e Clark (História Natural das Doenças).

a) Prevenção primária: promoção da saúde mental e proteção específica. Nesta fase, procurando identificar distorçōes ambientais familiares e individuais que venham afetar o indivíduo ou a comuridade no tocante a sua saúde mental;

b) Prevenção secundária: diagnóstico e tratamento. Nesta fase, tratando os indivíduos que apresentam doenças mentais, procurando prevenir aqueles e encurtar o período de incapacidade.

c) Prevenção terciária: reabilitação. Nesta fase procurando enfatizar o retreinamento e educação para utilização plena da capacidade que restou, após estabelecimento do processo mórbido.

5 - A programação não deveria apenas deter-se em medidas de prevenção secundária (diagnóstico e tratamento), que deveriam 
também ser desenvolvidas atividades de prevenção primária (promoção da Saúde mental e proteção especifica), com certos grupos de usuários do Centro de Saúde. Com relação à prevenção terciária (reabilitação), pensou-se que as medidas a serem levadas a efeito seriam basicamente aplicadas aos indivíduos que se beneficiariam de medidas de prevenção secundária (diagnóstico e tratamento).

6 - A partir dos pontos de vista firmados, os objetivos do programa de Saúde Mental do Centro de Saúde Experimental da Barra Funda são:

IV - Objetivos

"Promoção, proteção e recuperação da Saúde Mental de usuários do Centro de Saúde, a partir de uma problemática familiar e social dos mesmos, identificada e abordada pelos diversos membros de equipe de saúde, sob a responsabilidade de um médico-psiquiatra".

$\mathrm{V}$ - Equipe participante

- Médico-psiquiatra.

- Médico-sanitarista.

- Médicos consultantes (clínicos, pediatras, obstreta e ginecologista).

- Assistente Social.

- Enfermeira de Saúde Pública.

- Visitadoras de Saúde Pública.

A equipe de saúde, quando percebe distúrbios psíquicos, notifica os casos à simples suspeita, para isto usando a folha de notificação compulsória de doenças transmissíveis.

Assistente Social:

1 - Procede ao estudo psico-social da família, a fim de de-. tectar repercussões sociais significativas decorrentes da problemática apresentada.

2 - Propõe tratamento psico-social para o caso.

3 - Encaminha o caso suspeito ao psiquiatra, já devidamente informado sobre os fatores sócio-familiares condicionantes e o tratamento psico-social proposto.

Médico-psiquiatra:

1 - Toma conhecimentos das notificações e do encaminhamento do Serviço Social. 
2 - Ajuiza e analisa o caso e as condutas propostas marcando consulta para os casos de interesse psiquiátrico.

3 - Procede as consultas psiquiátricas marcadas determinando diagnóstico, tratamento e seguimentos necessários. Este seguimento subentende novos encaminhamentos para os demais profissionais, solicitação de visitas domiciliares, convocação de clientes e orientação para instituições especializadas.

4 - Procede a psicoterapia de grupos contando com a participação de outros profissionais da quipe de saúde.

Médico-sanitarista:

1 - Participa do planejamento geral da programação de saúde mental.

2 - Assessora os membros participantes da programação, dando enfoque quanto aos aspectos de saúde pública, visando um melhor aproveitamento e rendimento da programação.

Médicos consultantes:

1 - Fornecem ao médico-psiquiatra elementos diagnósticos identificados e condutas assumidas.

2 - Discutem com o médico psiquiatra, condutas psiquiátricas que possam assumir, dando prosseguimento ao tratamento de determinados casos confirmados.

Visitadoras de Saúde Pública:

1 - Executa visitas domiciliares onde reforçam condutas de tratamento e seguimento de casos.

2 - Colhe dados e informações durante entrevistas em pré e pós consulta, que possam contribuir para o esclarecimento do diagnóstico e condutas terapêuticas.

3 - Convoca clientes para consultas psiquiatras e para entrevistas com a enfermeira de saúde pública e assistente social.

As atividades da visitadora de saúde pública são direta e indireta supervisionadas pela enfermeira de saúde pública.

VI - No presente trabalho, destacaremos a atuação da enfermeira de Saúde Mental do Centro de Saúde Experimental da Barra Funda.

A enfermeira de saúde pública, em virtude de sua formação polivalente e sua participação em todas as áreas programáticas da Unidade Sanitária, pode atuar no programa de Saúde Mental e, baseando-se na linha de ação da Saúde Pública, propõe-se: 
1. - ao nível da comunidade:

a) identificar problemas familiares, scciais e culturais que possam interferir na saúde mental da comunidade;

b) colaborar com a equipe de saúde para melhor compreensão de situações individuais e da comunidade que influam na saúde mental da população;

c) levar ao conhecimento da equipe de saúde, intercorrências que repercutem na saúde mental da comunidade, propondo medidas que julgue necessárias;

d) participar das programações atuando dentro de seu campo específico, junto ao indivíduo, à família e à comunidade.

Esta atuação é possivel através de: execução de entrevistas, reuniōes com grupos, visitas domiciliares, planejamento de programas e reuniōes periódicas com a equipe de saúde.

2 - Ao nível dos usuários do Centro de Saúde.

Quanto aos usuários do Centro de Saúde, a enfermeira de saúde pública pode atuar nos níveis de prevenção propostos por Leavell e Clark, incluindo na:

1 - Prevenção primária, atividades dirigidas à família, grupos e comunidade, voltadas para a promoção e proteção específica em Saúde Mental. Alguns grupos em funcionamento no Centro de Saúde: Grupo de parto sem medo e grupo da saudade, cuja coordenação é da responsabilidade da enfermeira de saúde pública, com a participação dos demais membros da equipe. No grupo de parto sem medo, são incluídas gestantes que estão fazendo consultas periódicas no pré-natal. Esta atividade é baseada no programa do parto psicoprofilático (parto sem medo), visando preparar psicologicamente a mulher para uma gestação normal, um parto sem ansiedade, uma recepção adequada da criança. Caso a enfermeira identifique problemas psicológicos, por exemplo rejeição à gravidez ou à criança, discute o problema com o psiquiatra, o qual fixa a conduta a ser tomada. O grupo da saudade é formado por pessoas idosas que estão sem uma atividade profissional permanente e que, via de regra, apresentam excessiva preocupação com problemas de saúde, acarretando por isso um grande afluxo às consultas médicas, referindo na maioria das vezes sintomas puramente subjetivos, sem uma fundamentação clínica real. Para a inclusão no grupo, faz-se necessário uma entrevista preliminar com a enfermeira de saúde pública, e a partir disso os interessados são orientados para diferentes trabalhos manuais pela enfermeira ou visitadora de saúúde pública. Esta atividade artesanal é orientada no sentido de ocupação e não no cle terapia ocupacional. 
2 - prevenção secundária, (diagnóstico e tratamento), podemos destacar a atuação da enfermeira de saúde pública como um membro integrante da equipe de saúde quanto a atividades dirigidas ao indivíduo, à família e à comunidade.

2.1 - junto ao indivíduo (doente mental).

- A enfermeira deve identificar no decorrer de suas atividades específicas no Centro de Saúde, distúrbios psíquicos apresentados por aqueles que frequentem o Centro;

- Notificar os casos suspeitos, que passarão para o controle do médico psiquiatra;

- Participar de reuniōes com o médico psiquiatra para discussão dos casos já atendidos ou a serem atendidos;

- Fazer entrevista preliminar dos casos notificados, encaminhado-os após para estudo psico-social da família;

- Proceder a entrevista pré e pós consulta dos casos selecionados para consulta psiquiátrica;

- Fazer o controle e seguimento do tratamento de rotina de determinados distúrbios psíquicos (epiléticos, alcoólatras, etc.);

- Proceder a entrevista de seguimento de caso, toda vez que se fizer necessário.

\subsection{Junto à família e à comunidade}

As atividades são dirigidas especificamente para o Grupo de alcoolatras. Nestes grupos são incluídos indivíduos identificados como alcoólatras pelos vários elementos da equipe de saúde que procedem a notificação dos mesmos. Dada a possibilidade correta desta identjficação, os mesmos são encaminhados para a assistente social que prccede ao estudo psico-social da família e para a enfermeira de saúde pública. Esta, após uma entrevista preliminar, independente de uma consulta psiquiátrica, os inclui num grupo psicoterápico. Este grupo, chamado grupo de alcoólatras, funciona quinzenalmente às segundas-feiras, às 20 horas e é obrigatória a participação de algum nembro da família, uma vez que o alcoolismo não é úm problema individual, mas afeta principalmente o grupo familiar. Nas reuniōes participam: o médico-psiquiatra que procede a psicoterapia de grupo $\epsilon$ faz consulta individual após as sessões. A enfermeira de saúde pública que coordena e controla a frequência do grupo, dá informacões sobre o seguimento e tratamento estabelecidos, procede as pós-consultas médicas, faz convocaçōes para as próximas reuniōes de grupo. efetua as entrevistas de seguimento dos casos entre as reuniōes psicoterápicas. A enfermeira de saúde pública pode por delegação de função instituir alguns tratamentos, segundo uma rotina pré-estabelecida pelo médico-psiquiatra. Os alcoólatras com distúrbios orgânicos passam imediatamente a ser tratados pelos clínicos gerais Centro de Saúde. 


\section{3 - Prevenção terciária e reabilitação}

As medidas de prevenção são basicamente aplicadas aos indivíduos que se beneficiaram de medidas de prevenção secundária (diagnóstico e tratamento). Nesta fase a atuação da enfermeira de saúde pública é feita como nas fases anteriores juntamente com a equipe de saúde.

As medidas de reabilitação são basicamente aplicadas aos indivíduos que já passaram por um tratamento especializado com o nbjetivo de retreiná-lo para a utilização, a melhor possível, da capacidade que restou, após o estabelecimento da doença.

Junto às famílias e a comunidade, a atuação da equipe de saúde e em especial da enfermeira de saúde pública é a de:

- preparar a família para aceitiar a limitação da incapacidade, tentando obter a colaboração dela para um melhor aproveitamento e satisfação do doente;

- propor medidas preventivas e curativas de atuação;

- assumir programas que possam colaborar para a continuidade da saúde mental da população, através de técnicas educativas.

Estas atividades são desenvolvidas principalmente com grupos da comunidade.

Conclusões.

1 - A enfermeira de saúde pública com sua formação polivalente tem amplas possibilidades de atuar na programação de saúde mental, tanto em tarefas específicas como no processo de elaboraçãc do referido programa.

2 - A atuação da enfermeira de Saúde pública, para ser eficiente na área de saúde mental e especificamente em prevenção secundária e terciária, exige um trabalho em equipe, do qual participe um médico-psiquiatra.

3 - Para que este trabalho tenha repercussão social e, portanto, seja um trabalho de Saúde Pública, deve a longo prazo levar ^. uma participação da comunidade na programação. Para tanto o Centro de Saúde julga imprescindível, como etapa preliminar, desenvolver atividades junto à família. 